\title{
Reading the 'Sexy Oldie': Gender, Age(ing) and Embodiment
}

\author{
Tiina Vares
}

\begin{abstract}
In recent years there has been a cultural-scientific shift in the ways in which ageing and sexuality are represented. This has been most notable in the popular media where the predominant portrayal of asexual old age is increasingly accompanied by newer images of the 'sexy oldie'. While this shift counters conventional stereotypes of the asexual and disengaged elderly, the implications for seniors of such a change have not yet been adequately researched. Do senior viewers read images of sexy oldies as a challenge to traditional framings of older people as not sexually desirable, desirous, or capable? Do such portrayals disrupt the 'unwatchability' of elderly bodies and sexuality? This article draws on material from a reception study of seniors' readings of the film The Mother (2003) and focuses on the tensions and contradictions within and between the responses of focus groups of men and women (aged 49-85). In particular, I explore the ways in which some female participants' affective responses of 'disgust' to a filmic image of a naked, sexually active woman in her 60s, work to reconstitute it as 'unwatchable'.
\end{abstract}

Keywords: ageing, gender, representation, sexuality

Until the 1990s, sexuality and old age were primarily understood as contradictory, oppositional or incompatible (Gott, 2005; Calasanti and Slevin, 2006). With the dominant framing of later life as 'asexual', popular cultural portrayals of sexually active/engaged older people were generally confined to 'humourous' greeting cards in which the 'joke' played on notions of seniors as not sexually desirable, not sexually desirous and not sexually capable (Calasanti and Slevin, 2006). The absence of portrayals of later life sexuality was notable in television, advertising and film. For example, in his study of prime time television in the United States, John Bell, found that, 'sexuality is generally removed from the lives of elderly characters' (1992:309). Advertising was also marked by a general absence of older people, in particular, those who were sexually/romantically involved (Williams et al., 2007:3). Likewise, few films portrayed older men and women as sexually involved with each other (Markson, 2003; Bildtgard, 2000).

Representations of elder sexuality were thus 'essentially taboo for mainstream culture - possessing an intrinsic "unwatchability"' (Williams et al., 2007:2). Williams et al. 
draw on Kathleen Woodward's (1991) notion of the 'unwatchability' of images of elderly nudes and apply it to later life sexuality. Justine Coupland also uses this concept to explain how 'even mildly sexual scenes' between actors in their 60s in an episode of the television soap opera Eastenders provoked large numbers of written complaints, which described the scene as 'revolting', 'horrible' and 'unnecessary' (2000:13), that is, as 'unwatchable'. There is, however, a gendered dimension to the 'unwatchability' of portrayals of later life sexuality which is not signalled in the accounts above. In film, for example, it is the older woman's body which remains hidden from the spectator (Markson, 2003:99) and is not displayed nude or semi-nude even if portrayed in a sexual role (Oberg, 2003:116). This reflects a gendered 'double-standard of ageing' (Ginn and Arber, 1993; Sontag, 1997) in which older men are more likely to be portrayed as competent and sexual, while older women are rarely seen as 'capable and independent, never as sexually attractive' (Itzin, 1986: 126). Thus, although countless films portray older men as romantically and sexually involved with younger women it is rare for the love object to be an elderly woman (Markson, 2003: 92). There are two notable exceptions: The Graduate (1967) and the cult film Harold and Maude (1971), however, in both films the sexual activity is implied rather than seen.

In Harold and Maude, for example, Maude's semi-naked, sexually engaged body is never seen. Hal Ashby, the director, faced pressure from the studio which prevented him from filming Maude (aged 79 and 3/4) and Harold (around 20) 'making love':

We didn't actually have a scene of them making love, but I wish I'd shot it. ... Paramount said it would be too tough for people. I said, 'That's sort of what the whole movie is about, a boy falling in love with an old woman; the sexual aspect doesn't have to be distasteful'. They said it would turn everybody off. I was crazy about the footage. But it was a losing battle (Ashby cited in Shedlin, 1972) (italics added).

The film, in fact, provides a particularly loaded commentary on what the viewer is not seeing when a priest tells Harold:

I would be remiss in my duties if I did not tell you that the idea of intercourse and the fact of your firm, young, body commingling with withered flesh, sagging breasts and buttocks makes me want to vomit (cited in Markson, 2003:92-93) (italics added). 
Here, the sexually active, unclothed older woman's body as imagined by the priest (and potentially the viewer) provokes revulsion. It is a body that should not be seen, which remains 'taboo' (Markson, 2003:98), and which provokes 'almost visceral disgust' (Melamed cited in Sobchack, 1999:202). What then happens when elder sexuality and, in particular, the sexual, semi-naked older woman's body become increasingly visible in popular culture?

\section{Enter 'Sexy Oldies'}

Since the 1990s representations of the 'sexy oldie' (Gott, 2005) have appeared in advertising, television and film. These can be located within a cultural scientific shift in which lifelong sexual function has become a primary component of achieving successful ageing in general (Katz and Marshall, 2003:12). Print and television advertisements for products as diverse as Viagra (and other 'Erectile Dysfunction' medications), Olivio, Continental Soup and Telecom now portray older couples as romantically and/or sexually engaged. Films such The Cemetery Club (1993, Directed Bill Duke) and Autumn in Paradise (1995, Directed by Richard Hobert) also portray images of elderly couples' sexuality. What we have here is 'a new kind of representational practice in popular culture' (Gill et al., 2005:38) in which older bodies are depicted as erotic/sexual. Such representations potentially challenge the invisibility/unwatchability of later life sexuality and the double standard of ageing.

However, Bildtgard's (2000) analysis of nine films representing later life sexuality (which screened in Sweden between 1990-1995) indicates that such representations are double-edged. Although these films appear to challenge discourses of asexual old age, the portrayals of sexual relationships between seniors are limiting because they 'have to be affectionate' or romanticized (2000:173), and 'elderly people who are sexually active have to be "well-preserved"" (2000:174). Furthermore, the gendered double-standard of ageing is at work in all nine films with elderly women portrayed less often than sexually active elderly men and the usual sexual combination being that of an elderly man and a younger woman (with no examples of the opposite situation) (Bildtgard, 2000:175-6). Bildtgard also highlights a 'significant silence' in that 'none of these films actually shows an elderly couple having sex, it is only hinted 
at' (2000:176). Thus, the common assumption that elderly people's sex lives are more or less non-existent is reconstructed (Bildtgard, 2000:180).

The more recent films Something's Gotta Give (2004, Directed by Nancy Meyers) and The Mother (2003, Directed by Roger Michell) potentially contest the double standard of ageing with their portrayals of older women in sexual relationships with younger men (as well as men their own age). The Hollywood movie Something's Gotta Give provides perhaps the first mainstream representation of a naked, sexually active woman in her 60s (Erica has a sexual relationship with Julian, in his 30s, and Harry, in his 60s, played by Diane Keaton, Keanu Reeves and Jack Nicolson respectively). However, The Mother ${ }^{l}$ is a more provocative and challenging film as it deals with a 'big taboo' (Stein 2004), that is, explicit sexual scenes between May/Anne Reid in her late 60s (played by Anne Reid) and Darren in his mid-30s (played by Daniel Craig). (In Something's Gotta Give the sexual relationship between Erica and Julian is never seen). Furthermore, The Mother depicts the semi-naked body of an 'ordinary' older woman. In his review Stein (2004) (employing gendered ageist stereotypes) describes May as, 'a dowdy, frumpy widow who would pass unnoticed almost anywhere'. Another reviewer writes, 'May is a pudgy woman of average looks who dresses in dowdy outfits that make her look a decade older still' (Rhodes, 2004). Even in the film itself, May describes herself as 'a shapeless old lump'. Thus, the film portrays not only a sexually agentic older woman who initiates a sexual relationship with a younger man, but also the semi-naked body of May which is 'not morphed by cosmetic surgery' (Markson, 2003:99). This is not a portrayal of a 'well-preserved' (Bildtgard, 2000) older woman (in contrast with Erica in Something's Gotta Give). The Mother also portrays the older female protagonist in a sexual encounter with an older man which is neither romanticized nor part of an emotional relationship in which sex is 'merely an aside' (Bildtgard, 2000:173).

In what ways might these new representational practices in The Mother challenge the 'unwatchability' of elder sexuality and the double standard of ageing? One way to address this question is with a textual analysis of the film. This will not, however, tell us how audiences 'will view these images' (Williams et al., 2007:19). With the exception of a few interpretive investigations, little is known about the processes through which media representations of ageing are socially negotiated (Hodgetts et 
al., 2003:420) ${ }^{2}$ and no studies (to my knowledge) explore how seniors engage with, make sense of, and/or potentially utilize filmic representations of 'sexy oldies'. 3 I argue that we cannot theorize how older men and women will respond to such representations from textual analysis or anecdotal accounts alone. In fact, anecdotal accounts point to some fascinating tensions which beg further investigation. For example, one reviewer of The Mother suggests that audiences find the image of the sexually active May disturbing:

The theatre in Manhattan was packed for today's early afternoon showing with well over half the audience in the range of May's age. That some were shocked or disturbed to see her disporting herself with erotic abandon in the arms of a much younger man is an understatement (Stein, 2004).

In contrast, another reviewer argues that the film should provoke 'cheering' from women, '[t]he women in the audience will cheer the idea that a young man, so handsome ... can indeed feel romantic love for a much older woman' (Karten, 2004). In order to explore this tension between May/ The Mother as potentially empowering and/or constraining for audiences (and female viewers in particular), this article analyses the responses of senior men and women to the film. How do seniors make sense of/negotiate with the filmic portrayal of May as a sexually active older woman (with both an older and a younger man)? In what ways do seniors' embodied experiences of ageing inform their readings of this representation/film? Are there differences and/or similarities between the responses of older men and older women, in particular, with respect to the un/watchability of the depiction of the sexy oldie in The Mother?

\section{Methodology}

In this article I address these questions in an analysis of the talk of 17 women (in 4 focus groups) and 13 men (in 3 focus groups) conducted in Christchurch, New Zealand in 2006. The participants were all middle class, heterosexual and Pākehā (i.e. non-Māori New Zealanders, of European descent) and over 49 years of age. Like Merryn Gott, I use a wider conception of 'older' because the term has taken on a particular meaning within sexual health research where 'older people' are typically defined as those over 50 years of age (2005:75). Ethical approval for the study was granted by the University of Canterbury Human Ethics Committee. 
The female participants were aged between 52 and 82 years of age:

$\begin{array}{ll}\text { Group 1 } & 5 \text { women aged 52-62 } \\ \text { Group 2 } & 4 \text { women aged 66-82 } \\ \text { Group 3 } & 4 \text { women aged 70-78 } \\ \text { Group 4 } & 4 \text { women aged 60-82 }\end{array}$

At the time of the focus groups: 13 women were married (often in second or third marriages); 2 were widowed and one was single.

The male participants were aged between 49-85 years of age:

$\begin{array}{ll}\text { Group 5 } & 3 \text { men aged } 49-56 \\ \text { Group 6 } & 5 \text { men aged 52-85 } \\ \text { Group 7 } & 5 \text { men aged } 62-78\end{array}$

At the time of the focus groups: 7 men had partners/were married; 3 were separated or divorced; 2 were widowed and one was single.

A number of recruitment procedures were employed. Initially advertisements were placed in newsletters and on the notice boards of a variety groups and clubs attended by older adults. As this drew only a minimal response, a more active recruitment method was used which involved seminar presentations at social group events attended by seniors. This enabled prospective participants to engage with the topic and gain a more in-depth understanding of what participation would involve. It also meant participants would know each other and thus potentially feel more comfortable talking about representations of later life sexuality. Four groups were recruited in this way. The other three groups were recruited using a snowballing technique in which one participant had read/heard about the project and agreed to talk to his/her acquaintances who then agreed to participate. Thus, with the exception of one person in one group who responded to a print advertisement, all participants were familiar with each other.

Focus group interviews took place between February and November 2006 in settings that were convenient for participants (participants offered their own homes). Prior to the focus group meeting participants were given a copy of the film The Mother to watch at their own leisure. This strategy breaks the time commitment for participants 
(watching and discussing a film would require 3-4 hours). While the overall time commitment for the participants remains the same, it is the context of viewing which differs. Viewing a film at home prior to the meeting gives the participants some flexibility. One potential disadvantage is that the film is not 'fresh' for participants. It is, of course, very hard to assess what potential influence the time between viewing and discussion has on a group's responses to the film (if any at all). Nevertheless, it is crucial to question the idea that viewing a film in the research setting provides more 'authenticity' of responses (see Dahlgren, 1992). All talk is contextual and each context will influence the conversation. Talk in any context cannot be taken as transparently meaningful, but rather should be seen as a complex social construct which is a product of the particular environment in which it occurs. As long as we acknowledge the particular context of the research and analyse our material accordingly, the viewing of a film prior to discussion is a useful and practical strategy.

Group discussions lasted between 1-2 hours and followed a semi-structured format. The discussion guide addressed: perceptions of ageing and sexual activity in later life: perceptions of media portrayals of ageing and sexual activity in later life; changes in attitudes towards ageing and sexuality; and responses to The Mother, for example: what stands out for participants (which scenes, characters and so on) and responses May's sexual relationships. In addition, a variety of print advertisements were also shown to participants (for example: ads for Viagra; Continental Soup: featuring an older couple in bed reading the Kama Sutra; and the 'Dove Campaign for Real Beauty') with the aim of facilitating more broad ranging talk about popular cultural representations of later life sexuality. However, in the context of the focus groups for this study, these advertisements provoked little response. The group discussions focused on The Mother, participants' experiences of ageing, physical changes associated with ageing and sexual relationships in later life.

Interviews were transcribed verbatim. A discourse analytic approach was used to identify: the various ways in which later life sexuality was understood/constructed, in particular, gendered discourses of ageing and sexuality; the discursive resources used to make sense of/interpret the filmic portrayal of later life sexuality in The Mother; and the tensions/contradictions within/between participants' talk around/ responses to 
later life sexuality and portrayals of sexy oldies. In this article I explore the tensions within and between the talk in the men's and women's groups. Female participants, for example, critique the invisibility of older women as sexual agents in the media and support older women being in relationships with anyone they choose (including younger men), yet many respond with disgust to the portrayal of May in a sexual relationship with Darren. Male participants, in contrast, accept this portrayal and some even find May 'attractive'. However, they simultaneously frame the bodies of women their own age (and older) as 'sexually unattractive'. My aim is to chart these complexities.

Like Gill et al. I argue that in characterizing my analysis as discursive, I am 'not intending to weigh into the rather sterile debates' about the material versus the discursive (2005:44). I also 'endorse the position of many writers in arguing that these dichotomies are not helpful: the material and the discursive are inextricably linked' (ibid.). Sara Ahmed (2004), for example, argues that we need to avoid the analytical distinction between bodily sensation, emotion and thought. Emotions are not 'in' either the individual or the social, but produced at the very surfaces and boundaries that allow the individual and the social to be delineated as if they were objects (Ahmed, 2004:10). Ahmed does not simply want to interweave the individual and the social, but to explore the way they take shape through each other, or even how they shape each other (2004:14) (italics added). Thus, emotions are performative: they involve not just corporeal intensities but also speech acts. At the same time they also generate effects (Ahmed, 2004:14, 84). For example, disgust, Ahmed argues, maintains power relations in the hierarchising of bodies (Ahmed, 2004:88). In the latter part of this article I consider the 'work that emotions do' (Ahmed 2004) with respect to the visibility of older women's bodies, in particular, the ways in which the disgust, self-disgust and shame, articulated by many female participants, re-produce the 'unwatchability' of the older, sexually agentic woman's body.

When presenting extracts from the focus groups I have omitted word repetitions and all speech hesitations (i.e. terms such as 'um' and 'ah'). The presence of three consecutive dots [...] indicates a portion of speech has been cut. Pseudonyms are used for all participants. The number following the pseudonym indicates the 
participant's age and the ' $G$ ' code indicates the focus group designation (Group $1=$ G1 etc.).

\section{The gendered double standard of ageing}

Participants in all focus groups identified, and critiqued, the gendered double standard of ageing in the 'media' and 'society'. The female participants, in particular, reflected on the way in which 'in the media [...] the older man can have as many young women as he wants but the reverse of that isn't acceptable' (Pamela, 70:G3). Older women are thus 'invisible':

Tania (52:G1): I don't see much of our age group being portrayed in the media. Do you? I don't see much of that at all. [...]

Anna (58:G1): [...] I'm really aware of the emphasis of youth in all the media, in every aspect of the media. I don't see mature sexuality portrayed, generally speaking, in a positive [way]. [...] I think we are quite invisible as older women generally speaking.

Both the media portrayal, and societal acceptance, of older men as sexual partners for younger women, and the invisibility of/resistance to older women as sexual partners for younger men, was framed as 'unfair'. Jane (82:G2), for example, bemoans the fact that 'men are allowed to be dirty old men, but women aren't allowed to be dirty old women'. In all the women's groups often lengthy stories about sexual relationships between older women and younger men were told to illustrate that such relationships can, and do, work. For example: a 60 year off woman who set off on a 'sex holiday' with younger men in mind (group 1); a 47 year old woman with a 27 year old man (group 2); a woman who married a man 18 years her junior (group 3); the New Zealand author Sue McCauley who had a relationship with a Maori teenager several years her junior (the subject of her book Other Halves) (group 3); and a 73 year old woman with a 53 year old man (group 4). If the relationship works for those involved, participants argued, it should be accepted, for example:

Doris (70:G4): I think if they're both free, I don't see anything wrong with it. Janice (71:G4): As you mentioned it's not that age disparity, it's how suited they are.

Doris (70:G4): Well, that's right. I don't see that the age should be a barrier. Janice (71:G4): It's interesting, isn't it? Because we accept, without question, if 
Doris (70:G4): [it's] the other way around

Janice (71:G4): a woman with an older man. But for some reason, there's a barrier between a woman with a younger man and I don't understand, it, no.

There was also admiration for women who succeeded in sexual relationships with younger men. Phyllis, for example, applauded a relationship between a 73 year old woman and a 53 year old man:

Phyllis (72:G4): [...] When she came down, you know, they had on identical [...] shirts and they looked very happy and I thought, 'Well, what should she be doing? What would the children want her to do - sit at home somewhere?' [...] I thought, 'Go girl, go!' you know, she was very happy.

Although the male participants also acknowledged and critiqued a double standard of ageing in the media and society, they simultaneously reproduced this as they framed having a relationship with a woman older than themselves, or even their own age, as undesirable. In other words, for many participants sexually attractive women were 14-20 years younger than themselves. Most men acknowledged that what constitutes an 'attractive' woman has shifted upwards in age as they have grown older, however, this did not include the bodies of women their own age:

Ian (50:G5): [...] [You need to] accept that every young woman is not potential to be seen as a [sex] interest. I have daughters who are 20. Whereas 10 years ago I would have thought a 20 year old very nice, it would be nice if she liked me - but now if she likes me I have got a problem you know. There is a difference because she is the age of my daughter. Whereas before I would think - you know - I have a 20 year old after me, eyeing me up - it is great. But now I am definitely older and I am not interested the same way. [...]

Patrick (56:G5): I have a daughter that is 19 and I agree something has happened somehow. It is a bit yucky. I think I now find 35 year olds are sensuous, not 19 year olds.

Philip (69:G7): When I look back to when I was much younger than I am now, when I was sort of round about 30, women of 40 years of age and older were unattractive. You know, I had no desire to sort of have any sort of intimate [relationship]. Although I could have good friends with women of that age I had no desire whatsoever for any sort of intimate relationship with women of 40 plus because they were just not attractive. Now that I'm 69 - but of course perhaps the fact that when I was 30 I had perfect eyesight and now I have very limited vision so that needs to be taken into account - but now at 69 I can 
actually find women of 55 very attractive but I couldn't when I was young.

Ray (78:G7): [...] The older man may not be attracted to his contemporary woman $[\ldots]$ He may find them unattractive and unappealing but he may find the younger women quite appealing. [...] Well, older women - I personally haven't found - it's very rare that I could find an older woman sexually attractive. [...] There's no attraction, very little attraction, in the older body, except occasionally some older women will show a bit of a flash of sensuality which is attractive, but not often.

Even though very young women are no longer seen as sexually attractive because of their similarity in age to participant's daughters, the 'contemporary woman' (who is around the same age as the male participants) is also not considered to be sexually attractive. This illustrates what Sontag refers to as the 'sexual disqualification' of ageing women, that is, the process whereby women's 'sexual value' and attractiveness 'drops' with age (1997:20). Men, in contrast, Sontag argues, remain 'sexually eligible' well into old age (1997). The male participants draw on and reproduce these discourses and do not reflect on their own bodily changes with ageing or how younger, or contemporary, women might see their ageing bodies. There seems to be an assumption that young women (around 20 years of age) will still find them attractive even though the men are 'no longer interested' (Ian). In other words, they do not question their own sexual eligibility in the same way they do for women.

\section{Ageing femininity: 'Sagging' bodies/breasts, sexual ineligibility and social invisibility}

All group discussions focused on the ways in which the physical changes associated with ageing are marked for women in ways they are not for men. Few participants (male or female) considered how ageing might impact on men's sexual eligibility/attractiveness. It was the image/idea of the 'sagging' older woman's body which recurred in most group discussions. For example:

Andrew (62:G7): But I think that's a very definite training that one has had as a young person, as a young man, to see young female bodies as being attractive. It's like our brains have been programmed to see those as the tones 
Matthew (73:G7): Those are the what?

Andrew (62:G7): As the tones, you know, the young, firm breasts.

[Many]: Yeah.

Andrew (62:G7): That there's been a huge, sort of almost, conspiracy to brainwash us to feel a certain way.

Matthew (73:G7): Do you think we should be trained to find

Andrew (62:G7): You see a pair of saggy old breasts and it's a turn off!

Matthew (73:G7): Yeah, you think we can train ourselves to see something sexual in saggy old breasts?

Andrew (62:G7): Maybe, but I'm not even prepared to try [laughs]

Joanne (62:G1): If I think of getting 'old' [...] much of what has to do with being older is negative.

Interviewer: And what it makes it negative?

Joanne (62:G1): I suspect that has to do with social stereotypes [...] especially for older women. Older women are saggy, unattractive.

Interviewer: Right. Not like men?

Joanne (62G1): Older men are distinguished.

Trish (52:G1): I think appearance isn't as important for ageing men. [...] Older women have become more invisible as time goes on within this society.

Joanne (62:G1): I think that is true. And I think that if I confess the truth that when I was young and attractive I would use that, not in any terrible way, but as one way of achieving power and influencing people. Now I feel more invisible and can't use those things effectively any longer. [...]

Rebecca (55:G1): I think advertising is influencing us a tremendous amount [...] [it] makes us think that the only thing that's okay is to look young or whatever. [...] There's a great obsession with the reduction of wrinkles and a young body to be alright.

The male participants above frame their response to 'saggy old breasts' as socially constructed as they explain how they have been 'trained' or 'brainwashed' to be 'turned off' to older women's bodies. They thus reflect on the ways in which such cultural images and metaphors are instrumental in constituting their desires and emotions (Holstein, 2006:323). This works to both explain and justify why they are not sexually attracted to women their own age. They do acknowledge that they could 'train' themselves to find 'saggy old breasts' attractive but, as Andrew says, are unwilling to even try. Here participants reflect on the way they are constituted by discourses and thus, in a sense, inevitably 'determined', as well as conceptualizing themselves as agents with the possibility for re-constructing their identities (which, in this context, they reject). 
Female participants also acknowledge the social construction of older women's bodies as 'saggy and unattractive'. In particular, 'social stereotypes' of femininity are reproduced through the media with its focus on reducing the visible signs of ageing in order to be 'alright'. As the 'accomplishment' (Laz, 2003) of femininity in western culture continues to be measured in terms of youthful physical appearance and sexual attractiveness, the physical changes associated with ageing can constitute a failure of sorts. One consequence is that older women undergo a 'process of transformation' in which they become 'socially invisible' (Oberg and Tornstam, 1999:633). For Joanne (and other female participants) this invisibility is experienced as a loss of power.

As with the older women in Frida Furman's study of beauty shop culture, the female participants' 'reading' of their bodies was in 'constant tension with images of youth'. (1997:104). 'Armed with negative, incapacitating images of old age' many women thus struggled 'to push away the reality' of their own ageing (Furman 1997:99). For example:

Justine (66:G2): That is part of getting old, when you look in the mirror and you see your body wilting, you're not that attractive anymore [...] I think when you're in your 40s and 50s you usually feel pretty good about how you look, but once you get to 55 and 65 you start to get rolls, and sags, and you don't feel so good about yourself anymore.

Paula (57:G1): [...] You stop looking in the mirror quite so often so it's not quite so upsetting.

Pamela (70:G3): [...] I often think if anything happened to [name of partner] I wouldn't want to meet another man because I would be so conscious about my body getting old and flabby and so on.

Jean (78:G3): You're so slim you don't have to worry about it [...]

Pamela (70:G3): But, I still feel that way. It's one of the down sides I think.

Interviewer: So you feel [bodily changes associated with ageing do] affect you in some ways?

Lorraine (74:G3): It's a constant fight against it. It's a constant fight against age.

Pamela (70:G3): Your body getting aged. I do physical things to combat it all the time.

Doris (70:G4): I don't like getting older looking. I hear people say, well they don't care, but I do. I mean I don't do anything silly about it, like have plastic surgery, but I don't like it. No, I don't like it all. I really dislike it. 
For these women the changes associated with ageing are described in negative ways such as 'wilting', getting 'rolls', 'sags' and 'flabby'. Many speak of not wanting to look in the mirror (like the women in Furman's book, Facing the Mirror) because they are 'upset' by what they see. Ageing is thus associated with loss of self esteem, no longer feeling (sexually) attractive and often accompanied by 'frustration' (Tania), embarrassment and shame (Kathryn). This is consistent with the studies by Laz (2003) and Fairhurst (1998) in which they suggest that, for women, appearance is the principle dimension of embodiment which includes shame and discomfort.

Some female participants, however, resisted the negative framing of ageing and reinterpreted the visible signs of ageing, for example:

Jane (82:G2): [How one looks as one ages] doesn't worry me. I'm quite proud of all the experiences I've had and I have a right to my wrinkles. They're justified by all the things I've experienced in my life.

Felicity (73:G2): It doesn't worry me, because that's what I think older age is - getting all these things. [...]

Jane (82:G2): [...] I think it's so sad that women can't accept ageing and not feel as though they are less sexually attractive.

The notion of 'wrinkles as markers of accomplishment' is what Furman refers to as 'one positive reading of the older body' available to older women (1997:115). As with some of the women in Laura Clarke's (2002) study, the participants above interpret wrinkles as signs of character and experience. For Clarke, this positive interpretation of wrinkles is an important means of resisting the beauty norms that dictate that older women's bodies are unattractive and undesirable (2002:440). Yet although some participants re-interpret 'wrinkles' and 'resist beauty norms', they simultaneously reject the image of the semi-naked, sexually engaged May in the The Mother.

\section{To look or not to look? Gendered embodiment and reading May}

One of the most striking features of the focus group discussions was the response of many women to the portrayal of May in a sexual relationship with Darren in The Mother. Although female participants critiqued the gendered double standard of ageing and enthusiastically discussed sexual relationships between older women and younger men most, however, responded with disgust to the filmic portrayal of May in 
a sexual relationship with Darren. For some participants this was related to May initiating a sexual relationship with her daughter's boyfriend, however, for others it was more specifically about the 'sight' of May in bed with Darren. For example:

Tania (52:G1): I found it bizarre because [May] was quite old. I mean I can imagine younger women going with a very young man. That I can understand. But she was getting old [...] She was just so old and the disparity between her and him was so great. I couldn't understand how he would find her attractive. [...] I just find it gross.

Felicity (73:G2): [In] the film, I just thought, when they got into bed, please keep it out of sight. Even though I quite approve of the woman having a sexual relationship with anyone she chooses if she's happy, I'm so conditioned, I just thought, please don't pull that sheet down. I didn't want to see an old bust, old and sagging breasts with this beautiful young body.

Justine (66:G2): Yes it was awful. I can't bear to see it. I'm all in favour of sex until you're 150 but I hate to see old women like that. I thought that was revolting, because she was older. [...]

Felicity's anxiety at the very idea of seeing 'an old bust, old and sagging breasts with this beautiful young body' is reminiscent of the words of the priest in Harold and Maude (above). While Justine is 'all in favour of sex until you're 150', neither she nor Felicity want to 'see' an older woman 'like that'. Whether female participants draw on dominant discourses in which physical changes associated with ageing for women constitute a loss of (sexual) attractiveness, or re-interpret these as markers of character and thus potentially of (sexual) attractiveness, they nonetheless respond to May with varying degrees of disgust. For example, Justine, at 66 years of age, no longer feels attractive, and could not 'bear to see' the image of May: it 'was revolting, because she was older'. However, while the physical changes associated with ageing do not 'worry' Felicity, she also responds to the image of May with, 'please keep it out of sight ... please don't pull that sheet down.'

In contrast, male participants accepted the portrayal of May in a sexual relationship with Darren and none expressed anything approaching disgust in their talk about the sexual scenes. In fact, they discussed the relationship in relative detail (in comparison to the women who resisted talking about it) and some found May 'attractive':

Howard (53:G6): I think that if you imagine a woman who happens to be older, you think 'oh she's not going to turn me on'. But, in fact, if you give it 
time and you end up in a situation where things can happen, as they did in this movie, the way they tend to develop, I think it can become very satisfying for both parties in spite of an age difference. [...]

I thought [the first sex scene between Darren and May] was very sensitively done, to be honest, and very realistic as well [...] She needed to ease into it, feel comfortable about the way that her body was reacting in front of this younger guy and judge his reaction to it and then after that, obviously, it then proceeded to penetrative sex. So I thought that was very realistic and I thought it was very well done.

Ian (50:G5): [May] needed a release, some memories and a friend, a loving friend [...] and she had a physical need as well as emotional. [...] [Darren] thought 'that is something I can give her which doesn't undermine me or the relationship with the daughter'. He just felt safe in that.

Nathan (64:G7): I actually found the older woman attractive.

Matthew (73:G7): Yes, so did I but not at the time that she was having sex.

In the context of the focus group discussions the male participants simultaneously frame women around their own age (and older) as sexually unattractive and suggest that this position can change as they engage with 'new' representational practices. As they talk about May they find her neither sexually unattractive nor are they 'turned off'. Most frame this portrayal of a sexually agentic older woman as 'moving', 'realistic' and one which 'makes a statement'. It also allows Patrick to think about older women as sexually 'desiring' and has the potential to open one's 'perspective' and give viewers 'permission' to see things differently. For example:

Patrick (56:G5): [...] [May] just wants a bonk, simple as that, and traditionally because she is older, because she is a woman, kind and gentle, you don't associate that with a primal lust [...] Because men have enough trouble, well in my generation we do, of thinking of women that way anyway.

Interviewer: As desiring?

Patrick (56:G5): Yeah, wanting it [...] A woman like my grandmother simply wanting sex - no - I wouldn't have though of it.

Bruce (49:G5): It takes courage for people to look at [a media image of a sexually active older women] and it means you have to be introspective and look at yourself and sometimes it takes sheer guts and honesty to admit, maybe I'm wrong [with how I think about this image].

Alex (52:G6): Can I suggest that a [representation of May as a sexually active older woman] doesn't necessarily consciously convince you to 
do something. What it does do is erode your prejudices to situations that are not [seen as acceptable]

Howard (53:G6): Yes, exactly. It doesn't encourage us to do it, it just simply takes away

Alex (52:G6): It gives us more permission.

Mark (54:G6): It opens our perspective on the situation.

These participants describe the film as offering viewers the possibility of thinking differently about, and challenging, normative understandings of femininity, ageing and sexuality. For Bruce this requires 'courage', 'introspection' and 'guts' in order for a viewer to reflect on their existing ways of thinking or 'prejudice' (Alex). Alex does not argue for a simplistic 'cause and effect' model in which the film directly influences behaviour, but rather a more subtle process of meaning contestation which opens up spaces, and gives permission, for viewers to challenge dominant discourses of older women as not desiring or desirable. They also suggest that the film will potentially impact on female viewers:

Mark (54:G6): [...] It might encourage a woman of the same age as what the mother was in that film, to say that 'I don't need to deny myself this'. Sure it has an impact. [...] People can relate to characters in movies and say, 'okay that's a possibility for me. It's okay to do that because someone else is doing it'.

Nathan (64:G7): I wouldn't be surprised if some [women] would be stimulated by seeing the film saying, 'I'm in a similar situation and why don't I break out and be myself, my sexual being'.

Yet, as illustrated above, many female participants do not even want to look at this 'new' representation. In 'performing' (Ahmed, 2004) disgust or revulsion as they engage with an image of an older woman's body they in fact re-produce this body as disgusting. Emotion, such as disgust, is not either 'in' the participants or the image of the ageing woman's body, but is an effect of the encounter which draws on cultural norms, discourses and histories (Ahmed, 2004). Both male and female participants draw on discourses of ageing femininity and thus, in one sense, 'must already know' that the ageing woman's body is 'disgusting' (Ahmed, 2004:10). In other words, they have an image of the old woman's body which is shaped by cultural discourses and memories, for example, the cultural 'revulsion to the specificity of female ageing' (Kaplan, 1999:172). Yet, in the encounter with the image of May, it is only the female participants who reject this body and re-produce it as disgusting. 
This raises the question: what does it mean to feel disgust for/reject an image of a body that is, in many ways, similar (in terms of age and gender) to one's own? For Ahmed, disgust is attributed to an object or other (that is, 'badness' gets 'expelled' and 'sticks' to the bodies of others) (2004:104). Shame, in contrast, is a 'bad feeling' attributed to oneself, and self-disgust is closer to shame because the 'badness sticks' to oneself (ibid.). Thus, the emotions felt or articulated by female participants are closer to self-disgust because the bad feeling is also attributed to their own bodies, as illustrated in their talk about feeling dislike, embarrassment and shame for the changes in their bodies as they age (see also Hurd, 2000; Furman, 1997). In this context the boundary between disgust for an/other and self-disgust/shame for oneself blurs, that is, it is not possible to 'expel' the 'badness' completely because the participants 'embody the very discourses and bodily knowledges' (Murray, 2005:160) of ageing femininity.

What is significant in this study is the 'work emotions do' (Ahmed, 2004) with respect to the visibility of the older woman's body, in particular, the rejection of 'the sight' of May, as well as participants' increasing resistance to looking at themselves ('you stop looking in the mirror quite so often') and being seen by others ('I wouldn't want to meet another man because I would be so conscious about my body'). Participants' anxieties about both looking at and being seen were translated onto the sexually engaged body of May in the film. This is demonstrated in this final extract which refers to a sexual encounter in which May was lying face down on the bed as Darren penetrated her from behind:

Kathryn (70:G2): I thought it was very revealing that the old woman lay on her front so the younger man only saw the back of her

Felicity (73:G2): [...] I thought that was very revealing. [...]

Jane (82:G2): So he couldn't look at her.

Kathryn (70:G2): And he didn't want to. And she didn't want to be seen.

Shame, Ahmed writes, feels like an exposure/ a failure through the gaze of an ideal other, but it also involves an attempt to hide $(2004: 103,106)$. In this reading of the scene, participants identify with the 'ideal other'/Darren (who does not want to look at the 'old woman') and the 'old woman' who does not want to be seen (or is ashamed of being exposed). May's physical position is thus read as an 'attempt to hide' because, as Erikson says, 'in shame, one is visible and not ready to be visible' 
(cited in Ahmed, 2004:104). The participants, I would suggest, are also not ready for the visibility of an ageing woman's body because it is an exposure of sorts for them ('please don't pull that sheet down', 'keep it out of sight', 'I can't bear to see it').

Margaret Cruikshank suggests that, [t]he shame of aging is perpetuated when old bodies are hidden from view'. Although 'young naked female bodies are everywhere,' Cruikshank laments the absence of naked bodies of older (2003:149). Following this logic, the visibility of ageing women's bodies will enable ageing to be seen and experienced as less shameful. Likewise, Martha Holstein argues that, for older women, 'to not be seen is the ultimate devaluation' (2006:339). Yet, the talk of many female participants in this study complicates this argument that the increasing visibility of older women as 'sexy oldies' is necessarily 'positive', enabling or empowering for women. In other words, for many participants, the visibility of an older woman's body does not undermine its devaluation. Rather, to be seen 'is the ultimate devaluation'.

\section{In/conclusion}

This discussion raises far more questions than it is able to address. Although the men and women in the focus groups identify and critique a gendered double standard of ageing, it is only the male participants who read the filmic portrayal of May as enabling viewers, as well as themselves to think about femininity, ageing and sexuality in new ways. In contrast, many female participants do not 'cheer' or give themselves 'permission' to look at this portrayal, even though they critique the invisibility of older women and experience this as disempowering. Gendered embodiment in ageing is, I suggest, central to contrasting responses to May as a 'sexy oldie'. The older women in the study 'embody the very discourses and bodily knowledges' (Murray, 2005:160) of ageing femininity (which they simultaneously critique). Their responses to the physical changes associated with ageing, and the portrayal of May, indicate that it is difficult to 'completely remove [themselves] from the discourses that constitute [them] as subjects' (Murray, 2005:159). Or to put this another way, 'can we remove ourselves from the knowledges that have become so embedded in our sense of self, simply by changing our minds about our [old] bodies?' (Murray, 2005:161). The notion of 'changing our minds about our bodies' is not 
about reifying the body/mind dualism, but rather that historically and culturally specific tacit bodily knowledges are embodied and deployed constantly (Murray, 2007). And one of the ways bodily knowledges of ageing femininity are embodied by some female participants is through the corporeal intensities and articulations of disgust, self-disgust and shame. The affective responses to May thus work to complicate the argument that new representational practices of 'sexy oldies' necessarily disrupt the unwatchability of ageing femininity.

\section{Acknowledgements}

I am immensely grateful to the participants in this study and to the College of Arts, University of Canterbury for funding the project. I would also like to thank my research assistant Karen Due Theilade for her enthusiasm, dedication, and extraordinary effort on this project.

\section{Endnotes}

\footnotetext{
1 The Mother (2003) is the story of May; a woman in her late 60s (played by Anne Reid) who on the death of her husband goes to stay with her family in London. While there she has an affair with Darren, in his 30s (played by Daniel Craig), who is a builder working for her son and in a relationship with her daughter. The sex scenes between May and Darren are quite explicit and we see an older woman as both sexually desiring and enjoying sex/orgasm. May's daughter's encourages May to go out with a man her own age, Bruce, whom she goes to bed with (a disturbing scene of coerced sex). The film ends with May's son taking her back to her home where she packs her bags and heads out into the world.

${ }^{2}$ See Hodgetts at al. (2003) for seniors responses (in New Zealand) to the TV documentary Golden Oldies; Chan and Leung (2005) who explore senior women's responses (in Hong Kong) to television advertisements of younger and ageing women; Healey and Ross (2002) who explore (UK) seniors' responses to images of ageing on television; De Lorme et al.'s (2007) analysis of seniors' responses (USA) to DTC prescription drug advertising.

${ }^{3}$ Vares et al. (2003) examine how men in their 20s, 30s and 40s respond to advertisements for Viagra.
} 


\section{References}

Ahmed, Sara (2004) The Cultural Politics of Emotions. New York: Routledge.

Bell, John (1992) 'In Search of a Discourse on Aging: The Elderly on Television', The Gerontologist 32(3): 305-311.

Bildtgard, Torbjorn (2000) 'The Sexuality of Elderly People on Film - Visual Limitations', Journal of Aging and Identity 5(3): 169-183.

Calasanti, Toni and Slevin, Kathleen (eds) (2006) Age Matters: Realigning Feminist Thinking. New York: London.

Chan, Shun-hing and Leung, Lai-ching (2005) 'Between Viewing and Consuming: How Aging Women in Hong Kong Negotiate Television Advertisements', Feminist Media Studies 5 (2): 123-140.

Clarke, Laura Hurd (2002) 'Beauty in Later-Life: Older Women's Perceptions of Physical Attractiveness', Canadian Journal on Aging 21(3): 429-442.

Coupland, Justine (2000) 'Past the "Perfect Kind of Age"? Styling Selves and Relationships on Over-50s Dating Advertisements', Journal of Communication 50(3): 9-30.

Cruikshank, Margaret (2003) Learning to be Old: Gender, Culture and Aging. Lanham: Rowman and Littlefield Publishers Inc.

Dahlgren, Peter (1992) 'What's the Meaning of This? Viewers' Plural Sense-Making of TV News,' in Paddy Scannell, Philip Schlesinger and Colin Sparks (eds) Culture and Power - A Media, Culture and Society Reader, pp. 201-217. London, Newbury Park, New Delhi: Sage Publications.

DeLorme, D., Huh, J. \& Reid, L. (2007): “"Others are influenced, but not me”; Older Adults' Perceptions of DTC Drug Advertising Effects', Journal of Aging Studies 21(2): $\underline{135-151 .}$.

Fairhurst, Eileen (1998) "“Growing Old Gracefully" as Opposed to "Mutton Dressed as Lamb" in Sarah Nettleton and Jonathan Watson (eds) The Body in Everyday Life, pp. 258-275. London and New York: Routledge.

Furman, Frida Kerner (1997) Facing the Mirror: Older Women and Beauty Shop Culture. London and New York: Routledge.

Gill, Rosalind; Henwood, Karen and McLean, Carl (2005) 'Body Projects and the Regulation of Normative Masculinity', Body and Society 11(1): 37-62. 
Ginn, Jay and Arber, Sara (1993) 'Ageing and Cultural Stereotypes of Older Women', in Julia Johnson and Robert Slater (eds) Ageing and Later Life, pp. 60-67, London: Sage.

Gott, Merryn (2005) Sexuality, Sexual Health and Ageing. Berkshire, UK: Open University Press.

Healey, Tim and Ross, Karen (2002) 'Growing Old Invisibly: Older Viewers Talk Television', Media, Culture and Society, 24(1): 105-120.

Hodgetts, Darrin; Chamberlain, Kerry and Bassett, Graeme (2003) 'Between Television and the Audience: Negotiating Representations of Ageing', Health: An Interdisciplinary Journal for the Social Study of Health, Illness and Medicine 7(4): 417$\underline{438 .}$

Holstein, Martha (2006) 'On Being an Aging Woman', in Toni Calasanti and Kathleen Slevin (eds) Age Matters: Realigning Feminist Thinking, pp. 313-334. New York and London: Routledge.

Hurd, Laura (2000) 'Older Women's Body Image and Embodied Experience: An Exploration', Journal of Women and Aging 12(3-4): 77-97.

Itzin, Catherine (1986) 'Media Images of Women: The Social Construction of Ageism and Sexism', in Sue Wilkinson (ed) Feminist Social Psychology, pp. 119-34. Milton Keynes, U.K.: Open University Press.

Kaplan, E. Ann (1999) 'Trauma and Aging: Marlene Dietrich. Melanie Klein and Marguerite Duras', in Kathleen Woodward (ed) Figuring Age: Women, Bodies, Generations, pp. 171-194. Bloomington and Indianapolis: Indiana University Press.

Karten, H. (2004) Review of The Mother

http://www.celebritywonder.com/movie/2004_The_Mother.html

Katz, Stephen and Marshall, Barbara (2003) 'New Sex for Old: Lifestyle, Consumerism and the Ethics of Aging Well', Journal of Aging Studies 17(1): 3-16.

Laz, Cheryl (2003) 'Age Embodied', Journal of Aging Studies 17(4): 503-519.

Markson, Elizabeth (2003) 'The Female Ageing Body through Film', in Christopher Fairclough (ed) Aging Bodies: Images and Everyday Experience, pp. 77-103. New York: Altamira Press.

Murray, Samantha (2005) '(Un/Be)Coming Out? Rethinking Fat Politics', Social Semiotics 15 (2): 153-163.

Murray, Samantha (2007) 'Corporeal Knowledges and Deviant Bodies: Perceiving the Fat Body’, Social Semiotics 17 (3): 361-373. 
Oberg, Peter (2003) 'Image versus Experience of the Aging Body', in Christopher Fairclough (ed) Aging Bodies: Images and Everyday Experience, pp. 103-139. Oxford: Altamira Press.

Oberg, Peter and Tornstam, Lars (1999) 'Body Images among Men and Women of Different Ages', Ageing and Society 19(6): 629-644.

Rhodes, Steve (2004): Review: The Mother.

http://www.celebritywonder.com/movie/2004_The_Mother.html

Shedlin, Michael (1972) 'Review: Harold and Maude', Film Quarterly 26(1): 51-53.

Sobchack, Vivian (1999) 'Cinema, Surgery and Special Effects', in Kathleen Woodward (ed) Figuring Age: Women, Bodies, Generations, pp. 200-211. Bloomington and Indianapolis: Indiana University Press.

Sontag, Susan (1997) 'The Double Standard of Ageing', in Marilyn Pearsall (ed) The Other Within Us: Feminist Explorations of Women and Aging,pp. 19-24. Boulder, CO: Westview Press.

Stein, Ralph (2004) 'Tough, Touching, Sometimes Funny Encounter with a Big Taboo', Review of The Mother, http://www.imdb.com/title/tt0323298/

Vares, Tiina, Potts, Annie, Gavey, Nicola and Grace, Victoria. M. (2003) 'Hard Sell, Soft Sell: Men Read Viagra Ads', Media International Australia: Incorporating Culture and Policy 108: 101-114.

Williams, Angie; Ylanne, Virpi and Wadleigh, Paul, Mark (2007) "'Selling the Elixir of Life": Images of Elderly in an Olivio Advertising Campaign', Journal of Aging Studies 21(1): 1-21.

Woodward, Kathleen (ed) (1999) Figuring Age: Women, Bodies, Generations, Bloomington and Indianapolis: Indiana University Press. 